\title{
Recalculation of the Faraday Constant Due to A New Value for the Atomic Weight of Silver
}

\author{
V. E. Bower, ${ }^{*}$ R. S. Davis,* T. J. Murphy, $\dagger$ P. J. Paulsen, $\dagger$ J. W. Gramlich, $\dagger$ and \\ L. J. Powell + *** \\ National Bureau of Standards, Washington, DC 20234
}

September 16, 1981

\begin{abstract}
A report of the Faraday eonstant as determined at NBS via silver coulometry and alomic weight meas urements is presented. The uncertainty of the reported result represents a five-fold improvement over measurements made at NBS 20 years ago. The result should eontribute to an analysis of the self-consistency of several oller fundamental constants measurements. Experimental details have been reported in other publications which are cited in the text.
\end{abstract}

Key words: Atomie weight; atomic weight of silver; coulometer; electrochemical equivalent; Faraday constant; fundamental constants; silver; silver eoulometer.

The Faraday eonstant, $F$, may be derived from the following relation:

$$
F=\frac{A_{r}(\mathrm{Ag})}{E_{\mathrm{Ag}}},
$$

where $E_{\mathrm{Ag}}$ is the eleetroehemieal equivalent of pure silver and $A_{r}(\mathrm{Ag})$ is the atomic weight of the silver used in determining $E_{\mathrm{Ag}}$. In 1975 , coulometrie measurements of $E_{\mathrm{Ag}}$ undertaken at the National Bureau of Standards [1]' achieved suffieiently high precision to warrant a careful re-evaluation of the purity of the silver used [2] as well as a more aecurate redetermination of its atomie weight [3]. This last work, which is the previous paper published in this issue of the Journal of Research, eompletes our efforts to measure $F$ via the silver coulometer. Our results are:

$$
\begin{aligned}
F_{\mathrm{NBS75}} & =96486.17(13) A_{\mathrm{NBS} 75} \cdot \mathrm{s} \cdot \mathrm{mol}^{-1}(1.3 \mathrm{ppm}) \\
F_{\mathrm{B} 169} & =96486.06(13) A_{\mathrm{Bl} 69} \cdot \mathrm{s} \cdot \mathrm{mol}^{-1}(1.3 \mathrm{ppm}) \\
F_{\mathrm{SI}} & =96485.44(14) A_{\mathrm{Sl}} \cdot \mathrm{s} \cdot \mathrm{mol}^{-1}(1.4 \mathrm{ppm})
\end{aligned}
$$

where the subscripts identify the electrical units used; that is,

NBS75 —electrical units as maintained at the National Bureau of Standards in March of 1975, the time of the coulometric measurements.

- Center for Absolute Physical Quantities, National Measurement Laboratory. V. E. Bower's present address: 9906 Pomona Drive, Bethesda, MD 20034.

t Center for Analytical Chemistry, National Measuremenl Lahoralory.

** Previous publications of this author have been under the name of L. P. Dunstan.

1 Figures in brackets indicale literature references at the end of this paper.
BI69-a eonvenient referenee set of "as maintained" eleetrieal units defined in ref. [4]. (BI is an abbreviation for Bureau International des Poids et Mesures (BIPM), the International Bureau of Weights and Measures in Sèvres, Franee.) We use $A_{\mathrm{NBS75}} / A_{\mathrm{BI} 69}=1-(1.2 \pm 0.1) \times 10^{-6}[5]$.

SI - eleetrieal units as defined in the Système International (i.e., absolute units). The transformation from NBS75 to SI amperes has been made by using what we believe to be the best available conversion factor, $A_{\mathrm{NBS} 75} / A_{\mathrm{SI}}=1-(7.6 \pm 0.5)$ $\times 10^{-6}[5]$, although this is by no means a closed question $[6,7]$.

All uneertainties, which have been given above in parentheses, are meant to correspond to one standard deviation. In addition, the draft recommendations of the BIPM [8] regarding the caleulation of uneertainty have been followed, the most noteworthy being that all uncertainties are combined by taking the square root of the sum of their squares to produce a total uncertainty. These procedures for computing uncertainty were also adhcred to in reporting the most recent measurements of the electrochemical equivalent of silver $[1,2]$ as well as in reccnt compilations of the fundamental constants $[4,6]$. In rcporting the new atomic weight of silver [3], however, a more conservative approach has becn taken. That is, if the BIPM recommendations were followed, the total uncertainty (at a level of one standard deviation) in the atomic weight of silver reported in ref. [3] would shrink from 0.5 ppm to $0.3 \mathrm{ppm}$ [9]. It is this Iatter uncertainty which we have used in the results reported above. The total uncertainty at a level of one standard deviation for $\boldsymbol{F}_{\mathrm{NBS} 75}$, calculated . 
according to the BIPM recommendations, is shown in table 1. Thus the new measurement of the atomic weight of silver reported in ref. [3] has reduced the role of atomic weight in the uncertainly calculation of the Faraday experiment from dominance to insignificance.

TABu 1. Estimate of Uncertainties in $F_{\text {Nas?3 }}$ from Known Sources

\begin{tabular}{l|c}
\multicolumn{1}{c|}{ Source } & Uncertainty (ppm) \\
\hline Electrochemical equivalent of silver & $1.3^{*}$ \\
Atcmic weight of silver & 0.3 \\
Combined uncertainty & 1.3 \\
\hline
\end{tabular}

- Funher detwils in Ref. [2].

Figure 1 shows the value of the Faraday calculated here as well as Faraday constants measured by other scientists. Point $D$ is the present CODATA recommended value of Cohen and Taylor [4], which is calculated from other physical constants via least squares. It may be noted that not only has the overall uncertainty in the Faraday constant been reduced through this determination, but the new value of the Faraday is now essentially the same as that calculated from the proton yromagnetic ratio determined by Kibble and Hunt [13]. No further work using silver coulometers is planned since it would be extremely difficuli to reduce the uncertainty of the measurements below their present values.

\section{References}

[I] Bower, V.E.; Davis, R.S. A new determination of the Faraday by means of the vilver cowlometer, in Atomic Masses and Fundamental Constanss.
Vol. 5. J.H. Sanders; A.H. Wapstra, eds. New York: Plenum Presa; 1976. $578-583$.

[2] Bower, V.E.; Davis, R.S. The electrochemical equivalent of pure silver-; A value of the Faraday. J. Res. Nat. Bur. Stand. (U.S.). 85(3): 175191; 1980 May-June.

[3] Powell, L.J.; Murphy, T.J.; Gramlich, J.W. The absolute isotopic abundance and atomic weight of a reference sample of silver. J. Res. Nal Bur. Stand. (U.S.). 87(1): 9-19, 1981 January-February.

[4] Cohen, E.R.; Taylor, B.N. The 1973 least-squares adjustment of the " constants. J. Phys. Chem. Ref. Data 2(4): 663-734; 1973.

[5] Taylor, B.N. private communication.

[6] Cohen, E.R. Status of the fundamental constants, in Atomic Masses and Fundamental Constants, Vol. 6. J.A. Nolan, Jr.; W. Benenson, eds. New York: Plenum Press; 1980. 525-540. See especially p. 533.

[7] Taylor, B.N. Is the present realization of the absolute ampere in error? Metrologia 12: 81-83; 1976.

[8] Giacomo, P.; News from the BIPM, Meeting of experts on the subject of expression of uncertainties, Draft recommendation on the statement of uncertainties. Metrologia 17(2): 69-74; 1981.

[9] Eberhard, Keith R. privale communication.

[10] Craig. D.N.; Hoffman, J.I.; Law, C.A.; Hamer, W. J. Determination ] of a value of the Faraday with a silver perchloric acid coulometer. J. Res. Nat. Bur. Stand. (U.S.). 64A(5): 381-402; 1960 SeptemberOctober.

[11] Marinenko, G.; Taylor, J.K. Electrochemical Equivalents of Benzoic and Oxalic Acid. Anal. Chem. 40(11): 1645-1651; 1968 September.

[12] Koch, W.F. The value of the Faraday via 4-aminopyridene, in Atomic Masses and Fundamental Constants, Vol. 6. J.A. Nolen, Jr. and W. Benenson, eds. New York: Plenum Press; 1980, 167-172.

[13] Kibble, B.P.; Hunt, G.J. A Measurement of the Gyromagnetic Ratio of the Proton in a Strong Magnetic Field. Metrologia 15: 5-30; 1979.

[14] Deslattes, R.D.; Henins, A.; Bowman, H.A.; Schoonover, R.M.; Car. roll, C.L and Bames, I.L.; Machlan, L.A.; Moore, L.J.; Shields, W.R. Determination of the Avogadro Constant. Phys. Rev. Lett. 33(8): 463466; 1974 August. We have used the authors' most current recalculation of their result.

\section{Comparison of Recent Deleminations of the Faraday}
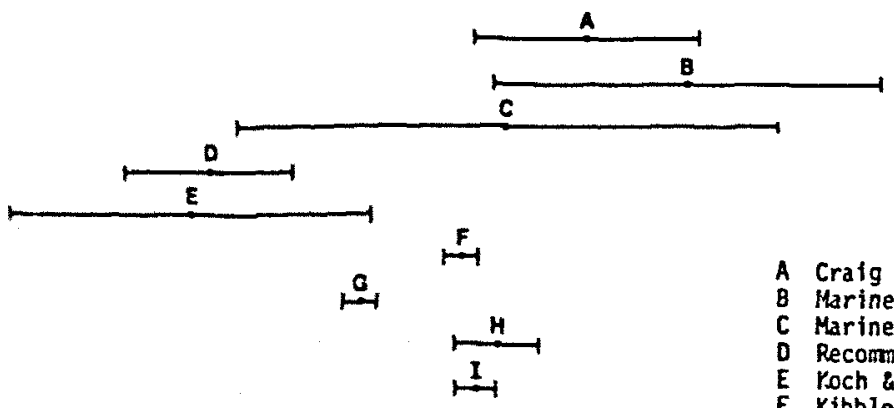

A Craig et al. [10]

B Marinenko \& Taylor [11]

C Marinenko \& Taylor [11]

D Recommended [4]

E Yoch \& Dieh1 [12]

F Kibble Hunt [13]

G Deslattes et al. [14]

H Bower Davis [2]

I This work

\begin{tabular}{|c|c|c|c|c|c|}
\hline$L$ & 1 & 1 & 1 & 1 & 1 \\
\hline 95:403 & 96484 & 96485 & 95486 & 96487 & 96488 \\
\hline
\end{tabular}

